\title{
Revistas ensambladas. Conceptualización de las publicaciones periódicas
}

\section{Assembling magazines. Conceptualization of periodical publications}

\author{
CARles MÉndez Llopis \\ Universidad Autónoma de Ciudad Juárez. Departamento de Diseño \\ cmendezllopis@gmail.com
}

Recibido: 11 de octubre de 2011

Aprobado: 1 de febrero de 2012

\begin{abstract}
Resumen
Es usual comprender las publicaciones periódicas que observamos diariamente como productos estructurados, lineales, concluidos, y la mayoría de las veces, disciplinares temáticamente. En contraste con este entendimiento, se expone una panorámica de aquellas revistas nacidas alrededor de los años 70 , que dinamizan y, hasta cierto punto, dinamitan, estas concesiones que de forma natural otorgamos a este medio: las revistas ensambladas. Unas publicaciones que han servido como alternativas creativas a la normatividad editorial mercantil, y que suponen un cambio en intención y disposición lectoras, deviniendo en una legibilidad conceptual y emocional. Iniciando con un breve recorrido histórico de los sucesos dialécticos entre arte y diseño, contextualizaré la conformación y el surgimiento de estas revistas, para descomponerlas formal y estructuralmente, así como en su contenido, para finalizar con la exposición de algunos ejemplos representativos de dichas publicaciones.
\end{abstract}

Palabras Clave: revistas artísticas, lectura, legibilidad.

Méndez Llopis, C. (2012): Revistas ensambladas. Conceptualización de las publicaciones periódicas. Arte, Individuo y Sociedad, 24 (2) 195-209

\begin{abstract}
It is common to understand periodical publications that we observe daily as structured products, linear, completed, and most of the time, with disciplinary theme. In contrast to this understanding, this paper provides an overview of those magazines arising around the 70's, which energize and, to some point, dynamite these concessions that we naturally attach to this media: the assembled magazines. Publications which have served as creative alternatives to commercial publishing regulations, and involve a change in reading intention and disposition, that become as a conceptual and emotional legibility. Starting with a brief history of the dialectic events between art and design, I will contextualize the shaping and emergence of these magazines, to decompose them, formal and structurally, and in their contents, to finish with the presentation of some examples of such publications.
\end{abstract}

Key Words: art magazines, reading, legibility.

Méndez Llopis, C. (2012): Assembling magazines. Conceptualization of periodical publications. Arte, Individuo y Sociedad, 24 (2) 195-209

Sumario: 1. Anotaciones históricas, 2. De las otras revistas, 3. De la norma al ensamblaje y viceversa, 4. Algunos ejemplos, 5. A modo de cierre. Referencias bibliográficas. Referencias electrónicas. 


\section{Anotaciones históricas}

En principio, proyectamos cualquier publicación como una voluntad de difundir un conocimiento generado - previamente-, el cual se informa a otros a través de un formato específico de comunicación -y hasta hace poco, de forma eminentemente impresa-. En este sentido, no podemos negar que la virtualidad ha alterado, no sólo la comprensión y asimilación de la información, sino principalmente su propagación, generando escenarios de conocimiento que progresivamente toman presencia de forma más eficaz y simultánea.

Trasladándome a un posible punto de origen -entre muchos otros-, la inauguración y ascendencia de este entendimiento actual de la información se podría situar junto a la llegada de la imprenta al mundo occidental, como revolucionario inicio de la difusión del conocimiento. Una revolución que desarrollaría parámetros editoriales ya tradicionalmente conocidos como paginación, espaciado, sangrías, saltos de párrafo, etc. Desde su invención, a lo largo de los años, hemos podido observar paralelamente el basamento de su formalización con la aparición de las empresas papeleras, el inicio de las traducciones, las búsquedas renacentistas de cánones estandarizantes, los estudios caligráficos y las experimentaciones tipográficas. Muy pronto, no sólo se posibilitaría la compilación progresiva del conocimiento en enciclopedias o diccionarios, sino que con el paso de la economía manual a la mecanización industrial, se aumentaría la capacidad de producción expansionando el comercio y las comunicaciones. Contexto en el que, complementado con el progreso tecnológico, energético y económico de la Segunda Revolución Industrial, destacarían la litografía y la fotografía como grandes técnicas revolucionarias de la comunicación visual, liberando la inflexible retícula de los tipos móviles, incorporando ilustraciones a mano o documentando gráficamente.

Evidentemente, en esta época de experimentación e innovaciones industriales, los diferentes círculos intelectuales y creativos fueron desarrollando movimientos culturales que eran perfectos representantes de los heterogéneos comportamientos gráficos y la generación de estilos editoriales. Habiendo pasado por la Kelmscott Press y el Art Noveau, entre muchos otros, se daría inicio al siglo XX con unos sólidos $-\mathrm{y}$ en ocasiones, cerrados- trazados a imponerse en la exposición y estructuración de contenidos de las publicaciones, es decir, no sólo qué debían contener -en cuanto a redes temáticas de interés para la población meta en tributo a los objetivos mercantiles-, sino también cómo contenerlo y organizarlo a favor de la funcionalidad/legibilidad: "Desde finales del siglo XIX la sociedad moderna impone sus planteamientos respecto a los medios de comunicación de masas, por norma las publicaciones literarias y artísticas venían siendo realizadas de una manera industrial, la tecnología proporcionaba una fácil reproducción que atendía y contentaba la poca demanda" (Gómez, 2010, p.13). Bajo estas mismas premisas, las publicaciones de creación eran desarrolladas industrialmente, sometidas como todas las demás a los parámetros tecnológicos de la época que permitían una reproducción eficaz, más económica y masificada. Pero algo estaba cambiando. De forma temprana llegarían los planteamientos de la Vanguardia: una mirada diferente de la creación, la comunicación y el lenguaje. Es el momento en el que se experimenta con todos los límites editoriales conocidos para expandir las fronteras y proponer alternativas. Nuevas posibilidades que empujaban con empeño lo anteriormente aceptado como 
norma a través de las mismas publicaciones que las diferentes corrientes utilizaron para autodefinirse, acotar objetivos, promulgar manifiestos, justificar sus posiciones y divulgar sus pensamientos.

A lo largo de este primer cuarto de siglo, incluyendo la gran influencia -en múltiples aspectos- que la Primera Guerra Mundial tuvo sobre las manifestaciones posteriores, surgieron una serie de publicaciones periódicas que supusieron grandes cambios para el lenguaje impreso y el concepto de revista en sí. Sin profundizar mucho en los diversos planteamientos, a grandes rasgos podemos observar: el amor por el movimiento del Futurismo, que dinamizó la tipografía, llenándola de expresión y sentimiento en múltiples composiciones; la estructuración del lenguaje impreso y el estudio de las leyes de organización visual del constructivismo; la provocación lingüística incondicional y libertad expresiva del dadaísmo, que -ya más centradas en la construcción y no en la destrucción- serán tomadas posteriormente por las investigaciones poéticas surrealistas; las experimentaciones geométricas y funcionales de la Bauhaus, y una gran etcétera de posicionamientos teóricos o prácticos que hicieron de esta primera mitad de siglo, un escenario de continuas transformaciones conceptuales en los desarrollos y evolución del lenguaje que originaron no sólo nuevas expresiones, sino también nuevas formas en el uso y lectura de éste.

Sería después de todas estas experiencias señaladas que inicia la segunda mitad del siglo XX, con la configuración de ciertas libertades y concesiones editoriales que no habían existido hasta entonces en las revistas normativas. Gracias al minimalismo formal y sintetismo estructural posbélico -después del paso por la Segunda Guerra Mundial-, la improvisación expresionista de la Escuela de Nueva York y la experimentación deconstructiva en la comunicación visual de los años 60 y 70, se van ampliando los límites de la página y generando composiciones más independizadas de la estructura lineal convencional. Momentos en los que, como veremos en las próximas líneas, "se inicia un cambio donde la oferta editorial adquiere más notoriedad, es más plural y creativa, proliferan otros medios, materiales y técnicas más acordes con la nueva concepción de comunicación, se empieza a dar justa importancia a la ilustración, diseño, formato, color, materiales, etc. y pasan de ser meros difusores de noticias o conocimientos a transformarse en verdaderos espacios exposicionales de creación." (Gómez, 2010, p.13). Una situación que, debido a la revolución acaecida en las diferentes vertientes y campos de conocimiento dentro del marco cultural, nos proporciona una visión más cercana al mundo actual. Pues hoy en día, como sabemos, el conocimiento se ha mercantilizado, existen múltiples referencias de cualquier saber, y la tecnología y el software nos permiten un uso totalmente ecléctico y efectivo en nuestras creaciones. Un escenario, con tal potencial y desarrollo, que ha propiciado la yuxtaposición, el montaje, la repetición y reflexión de las capas comunicativas del lenguaje en una suerte experimentadora constante dentro, además, de una red interconectada con alcance a cualquier información, tanto digital como analógica, que coexiste en sus diferentes soportes y fórmulas comunicativas de consumo cultural (Vidal y Martín, 2010) 


\section{De las otras revistas}

Durante largo tiempo, arte y diseño se han interrelacionado para desarrollar estrategias y luchar por romper una y otra vez cualquier clase de normativa -práctica o teórica-, en un afán de evolucionar y conseguir, finalmente, mediante el uso del lenguaje, la expresión o la obra deseada. Pero hemos de ser conscientes de que si de revistas normativas hablamos, dicha normatividad suele tener el deber de ceñirse y atenerse a unos cánones editoriales estandarizados por la industria -no digo que sin ciertas libertades-, para llegar eficazmente a consolidarse en el mercado -sea cual sea su temática, tipo de consumidor, nivel de experimentación gráfica o distribución-. Tarifas que se han de pagar en orden de asegurar la legibilidad y la comprensión lineal de lo mostrado en ellas y que, pese a las muchas experimentaciones, es una consigna que sigue perdurando hasta la actualidad. Actuación lógica por otro lado, ya que por ejemplo, la lectura de un periódico -o de una revista-, en principio, debe cerrar sus variables e interpretaciones de contenido todo lo posible. Como producto concluido, no se espera que insinúe, sino que informe y profundice en un tema que es de interés para el lector. Las posibles interpretaciones o representaciones que sugiera entonces para del lector, correrían por cuenta de este último, nunca será un atributo promovido desde los orígenes de la publicación, sino la capacidad y carácter de quien se encuentre frente a su texto.

Teniendo como pariente al libro, hito portador del conocimiento y divulgación cultural, parecería no haber otros modos de comprender un progreso educativo/lector, sin embargo, en la actualidad esta noción ha evolucionado -modificado y ampliado-, rebasando las fronteras tradicionalmente dispuestas. Como comentaba, a principios del siglo XX, ya podían observarse los parámetros primarios de lo que un medio de comunicación "industrializado" debía contentar, normas que se difuminan y alteran hacia la década de los 60, consecuencia de las experimentaciones con nuevos materiales, tecnologías, técnicas y lenguajes que se generaron al poner como centro epistemológico el mismo acto comunicativo -e incluso los espacios en el que éste se manifestaba-(Gómez, 2007). Ya desde el magnífico Un coup de dés jamais n'abolira le hasard (Una tirada de dados jamás abolirá el azar) (1897 -aunque sería hasta 1914 a que fuera publicado por la Nouvelle Revue Française-) de Mallarmé, en la que el espacio poético era indisociable del espacio visual, las publicaciones como tales, dejaron de existir como meros receptáculos, para sobresalir como presencias e ideologías autónomas de creación, al lado opuesto de las estructuras tradicionales y organizándose como redes comunicativas para proyectos multiformes (Schraenen y otros, 2010). De este modo, a la experimentación de Mallarmé, le seguirían muchas otras, como las de Apollinaire, de Marinetti, las de Salvat-Papasseit, "las palabras en libertad de los futuristas, las tipografías espaciales de los constructivistas rusos, los objetos textuales de los dadaístas, los artefactos poéticos del surrealismo, los readymade de Duchamp, los objetos itinerantes de Fluxus, las provocaciones objetuales de Robert Filliou, la poesía visual de Joan Brossa, las publicaciones esotéricas de Dau al Set, los objetos poéticos de Guillem Viladot, los mapas de los situacionistas, las ediciones para mitómanos de Carlos Pazos, los calendarios existenciales de On Kawara o las partituras del grupo Zaj..." (Bonet, Tro y otros, 2010, p.55). 
En resumen, una serie de experimentaciones que quebrantaron el tradicional uso de la palabra y la imagen, que tomaron las publicaciones impresas y las transformaron en una nueva construcción simbólica, objeto de "otras" interpretaciones más esenciales y, en muchas ocasiones, extremas. Cuotas de vanguardismo que emergen de la experiencia vital, la cotidianidad y "la descontextualización de imágenes, mensajes y materiales de uso poco habituales, creando una dinámica red de absoluta actualidad, con altas dosis de ironía y crítica, planificada desde la autosuficiencia del DIY (Do It Yourself)" (Pastor, 2008, p.5) En sí, esta convergencia de literatura y plástica que acaece en las publicaciones de vanguardia es una de las consecuencias inmediatas del cambio producido entre las fronteras artísticas y los desplazamientos entre disciplinas: "La relación entre la crítica como forma literaria y la obra de arte deja de ser unilateral y se genera un carácter dialéctico de relación y de acoplamiento creativo. Si hasta entonces eran los pintores los que tomaban de la práctica escrita historias y modelos, a partir de la prosa del crítico y poeta de la modernidad Baudelaire, la pintura se convierte en el punto de partida y la guía para la literatura, la que le permite explorar nuevas retóricas visuales del texto. Con el tiempo, este incipiente transvase entre la palabra y la imagen facilitará la construcción y el diálogo de nuevos discursos sociales y estéticos, también ideológicos." (Bonet, Tro y otros, 2010, p.54) Por otro lado, esta situación analógica entre campos fungirá también como una de las causas que originen las futuras publicaciones, híbridas y sin sujeciones extralingüísticas.

Debemos comprender que estamos situados en un contexto cambiante y los lenguajes se expanden y entremezclan, "ya no existen fronteras entre las diferentes disciplinas artísticas, los contenidos, los formatos y los continentes en las publicaciones, nada tienen que ver con los de hace unas décadas." (Gómez citado en Pastor, 2008, p.6). Ahora "nuestro mundo utiliza un lenguaje rico y complejo, que poco o nada debe ya a la lengua escrita" (Millán en Sarmiento, 1990, pp.292-293), como ya se auguraba, caminamos por una mezcolanza e integración de las artes que invierte en nuevas formas de escritura, eclipsando las limitaciones históricas y sustituyendo simbólica y conceptualmente los principios comunicativos de esquemas determinados. Y dentro de esta concepción surgirían las herederas de las primeras revistas vanguardistas -al menos como perspectiva de trascendencia lingüística asociada al término de independencia, tomadas como objetos de experimentación y transgresión (Vidal y Marín, 2010)-, las otras revistas: las llamadas revistas ensambladas (assembling magazines). Una acotación -la de "ensamblada"-, que utilizaré seguidamente sin hacer distinciones con otras denominaciones -como revistas objeto, por ejemplo- que podrían resultar más exactas en cuanto a aspectos formales o intencionales, a razón de que no es tanto mi interés el delimitar terminológicamente cada uno de los formatos como el de aproximarme a algunas de sus inagotables interpretaciones, multiplicidad de su lectura y diversificación del conocimiento que ofrecen como alternativa a las dimensiones habituales.

Siguiendo las anotaciones de José Luis Campal (2001) esta denominación de assemblig magazine es tomada "de un proyecto de Richard Kostelanetz denominado Assembling" (s.p.). El mismo Kostelanetz comenta en su libro $A$ dictionary of the avant-gardes (2001) que: "The name is taken for Assembling (1970-83), which was founded by James Korn (1945), later a museum director, and Richard Kostelanetz, 
who also prepared a retrospective catalog for an exhibition in an alternative space. Scarcely the first, Assembling had a long life, second only to Art/Life (1981), published monthly by Joe Cardella, and was consistently the thickest, serving the largest constituency of writer/artist self-printers" (p.37).

Publicaciones colectivas que tienen su origen entre los años 60 y 70 -sobre todo en Europa y Estados Unidos-, y que dan muestra de una superación y reacción ante las limitaciones de la tradición editorial frente al acto creativo. Una serie de revistas "confeccionadas exclusivamente con obras originales en las que el planteamiento fundamental de su contenido suele ser visual, el texto en ellas pierde la primacía y la importancia que puede alcanzar en otro tipo de revistas normalizadas o comerciales, queda subordinado por el atractivo que aportan formas, imágenes, objetos y texturas." (Gómez citado por Rodríguez y Clark, 2010, s.p.)

Tal y como Pilar Bonet (2010) anotaba, esta descendencia de las vanguardias, se amalgama en ellas sintetizando sus visiones y sumando vertientes, como la preconceptual de Marcel Duchamp cuando recopila en cajas y maletines disertaciones, bocetos, planteamientos y fotografías de sus obras; podemos divisar también las influencias de los fluxkit of fluxboxes de los años 60, con la documentación detallada de sus obras (instalaciones), seriada y ordenada en contenedores. Y como su propio nombre indica, este "ensamblar" diferentes obras en cada número expone asimismo las reminiscencias del punk y el Mail-Art, que amplió el contacto entre los artistas y formalizó una red de comunicaciones paralelas y alternativas al mercado editorial vigente (Gómez, 2010). Todo ello las convertirá, como veremos, en agentes híbridos transmisores de discursos dinámicos y colaborativos como alternativas reales a la normatividad lineal predominante.

Como en toda búsqueda de referencias y características, resulta casi imposible no recurrir a los lazos y parentescos familiares. He anotado cómo el libro de artista, con sus divergencias y alternancias históricas, podría contemplarse como el primogénito, ese hermano mayor reflexivo e independiente que imprime la crónica de las revistas. Resulta interesante para este planteamiento, comprender las publicaciones periódicas de las que hablamos teniendo en cuenta a éste como antecedente inmediato -al menos en la subjetivación creativa inicial-: "El libro de artista no es un libro de arte ni un libro para ser leído, sino una producción artística; una forma de expresión gestada en las combinatorias de diferentes lenguajes y sistemas de comunicación que aspira a transformar el acto de leer en el acto de mirar" (Bonet, Tro y otros, 2010, p.54). Así, si ellos son "libros como arte", formas híbridas y emocionales en el arte contemporáneo (Latour, 2010, p.37), estas publicaciones pueden calificarse del mismo modo "revistas como arte", es decir, expresiones artísticas seriables - que mantienen una "ejemplariedad"-, unificadas en formato libre y en periodicidad variable. Es importante resaltar en este punto, la indispensabilidad de la seriación y reproductibilidad de estas obras de arte, pues en su multiplicación reside la sustancia que transforma su estrategia comunicativa. Como "condición esencial de las obras y no sólo un medio de difusión de sucedáneos, hace que se operen en la relación entre el artista y el espectador, así como entre el artista y la obra, varios cambios significativos." (Rodríguez, Gracia y Murciego, 2008, p. 33). Una alteración germinada a través de lo múltiple que, alejada del valor otorgado históricamente al objeto único, ofrece "como 
factor añadido la capacidad de reproducción de una obra de arte realizada mediante estas herramientas, más incluso si la repetición forma parte de la misma obra, donde la multiplicidad ayuda a construir el discurso." (Martín-Jiménez, 2010, p.7)

$\mathrm{Y}$ precisamente, al conformarse a través de diferentes obras, composiciones $\mathrm{u}$ objetos, cada uno de los cuales tiene identidad propia -que forma metafóricamente cada una de las páginas, entendida como si fuera una revista convencional- es evidente que su lectura dista mucho de la tradicionalmente dispuesta en las otras. Juega por tanto con los lenguajes, sin pretender ser un producto concluido, sino una fuente de sugerencias a experimentar por el lector. Esta libertad, puede comprobarse en la unión y conjunción de gran cantidad de disciplinas, tantas casi como piezas y participantes de la publicación. En las revistas convencionales, los autores suministran texto e imágenes (la mayoría de las veces, ilustrativas del escrito o de la temática a tratar), pero en las revistas ensambladas, tanto la edición como la propia página es realizada por el creativo, pudiendo incluir -aunque suelen existir limitantes como por ejemplo el formato, alguna temática o la técnica- aquello que considere que debe conformarla. Pepe Murciego enlista: "Poemas objeto, visuales o discursivos, estampaciones, fotomontajes, collages, pequeñas esculturas, dibujos, serigrafías, electrografías, plantillas, sellos, fotografías, piezas de arte sonoro, grabados, postales, vídeos, linóleos, transparencias, cds, troquelados, maquetas, piezas de música experimental, recortables, partituras de acción, radiografías" (Rodríguez, Gracia y Murciego, 2008, p. 241), e incluso, dulces o sardinas enlatadas. Será el editor/coordinador el que funja de intermediario y ensamblador de todo este conocimiento -diferentes lenguajes- en un contenedor libre de normativas, pero fijado de antemano (Gómez, 2010)

\section{De la norma al ensamblaje y viceversa}

Entendiendo que la práctica de la comparación es poco deseable, pues constata que al menos dos términos pueden equipararse -siendo los objetos que aquí manejo totalmente diferentes-, pretendo seguidamente realizar un balance entre las revistas convencionales y las revistas ensambladas, observando una lista de discrepancias -aparte de las presupuestas e inmediatamente visibles-, que se atienen, de forma general, a las vías, modos y finalidades de su distribución, y de forma específica, a la muestra de contenidos, los lenguajes y cualidades de sus lecturas. Una serie de divergencias que -rechazando cualquier examen valorativo acerca de la conveniencia de unas revistas u otras- hacen hincapié en esas distancias que comprenden dos maneras totalmente diferentes de entender una revista y sus posibles lecturas, facultades, expresiones y posicionamientos.

En muchas ocasiones las revistas ensambladas han sido rechazadas por la economía de sus materiales (Gómez, 2010), una perspectiva surgida claramente de la estandarización del mundo mercantil editorial. Esta situación en gran medida forma parte por un lado, de la inexistencia de acotamientos comerciales para su realización, y por otro, de las nuevas vías comunicativas y procesos de creación que proponen. Obviar el mercado editorial no responde únicamente a su confección realizada a partir de originales múltiples, sino más bien a una actitud alejada, por un lado, de la búsqueda de lucro -no exentas de obtener beneficios económicos que las sustenten-, y por otro, de 
ser enmarcadas dentro de una disciplina, contenido o formatos específicos. Evidente, ya que, formadas en colectividad, "la pluralidad de lo ofertado no es traducible a ningún estilo, a ninguna moda, alejándose también de lo testimonial" (Gómez, 2010, p.17). Su carácter experimental postula por espacios minoritarios "que reconocen -y se reconocen- en su pequeñez" por lo que "gran parte de su energía se concentra en tejer relaciones de afinidad y amistad, nunca de interés comercial" (Rodríguez, Gracia y Murciego, 2008, p. 243). La distribución masiva o el establecerse como empresa comercial no tendrían cabida dados los parámetros expuestos, pues como digo, ni conciben grandes beneficios ni admiten la normatividad industrial estandarizante (Pastor, 2008).

Como sabemos, el funcionamiento de las revistas normalizadas suele estar fundamentado en estudios previos de mercado y se debe a su venta en él para existir; mientras que la ensamblada, al no estar basada en el intercambio comercial -al no tratar de enriquecerse monetariamente con el tiraje- sino en el placer de la subsistencia, puede mantener una distribución variable. Y este panorama de extrañamiento respecto de las convenciones editoriales sometidas a intereses económicos ha concedido, a lo largo del tiempo y simultáneamente, una serie de permutaciones en las diferentes fases del "juego" comunicativo: la figura del creador, respecto al libro o la revista común, pasó del rol "ilustrador" al de "realizador", algo similar a la relación de la imagen con el mismo texto. Ahora la imagen no ilumina la palabra sino que es la palabra la que racionaliza la imagen, el texto atrapado por el mensaje iconográfico (Barthes, 1986). Una ruptura que permite nuevas relaciones que escapan a la coyuntura comercial y a la institucionalización. Es lógico, por tanto, deducir que también la lectura convencional cambiara, pues la contemplación normativa y el registro verbal se vieron ampliados a otros códigos basados en una libertad de mensajes llena de tonalidades discursivas. Un cambio que a su vez, contaminaría la actitud y función del consumidor/lector, que ahora se ubicaría en otro lugar: el de productor e intérprete. Un nuevo "comprador" que emerge como "figura que eclosiona con la crisis del papel y la euforia de la red global, en la década de los noventa" (Vidal y Martín, 2010, p.6). Naturalmente, una euforia concebida también desde la perspectiva del creador, que parte de las múltiples posibilidades expresivas de individualización que el capitalismo global permite. Nuevas herramientas para la creación que simultáneamente conciben nuevos modos de "consumo" (Lipovetsky, 1996).

De este modo, las publicaciones convencionales tendrán un alcance generalizado mientras las otras, dada su edición y "forma de consumo", mantendrán uno minoritario. Es lógico que las primeras, apoyadas por su estructura mercantil e industrializada, superen los 3.000 ejemplares -llegando a los 30.000 o 50.000 dependiendo de su distribución-; mientras que las segundas asuman de 20 a 100 ejemplares (aunque algunas lleguen a los 1.000, e incluso de forma excepcional, logren comercializarse en los círculos mercantiles)

Todo lo anterior implica para unas, un consumidor pasivo de lectura lineal, y para las otras, uno activo y participativo -atendiendo a que estas características no son exclusivas, pueden pertenecer al mismo sujeto y dependen de la predisposición de éste-. Es comprensible por tanto, que si las revistas convencionales se regulan bajo normas mercantiles, obedezcan a una periodicidad cerrada, establecida e invariable, 
con pocas excepciones. Por el contrario, la periodicidad de las revistas ensambladas puede ser abierta, sin acotaciones, sometida a las dificultades creativas o la edición de cada número, aunque también las hay que afianzan su periodicidad, cumpliéndola con rigor. De una u otra manera, su adquisición se posibilita sin intermediarios -entre creador y lector-, pues "no son necesarios museos, ni galerías, su relación no es necesariamente mediada por críticos, ni historiadores". (Rodríguez, Gracia y Murciego, 2008, p. 31)

Es así como estas estrategias que vengo mencionando -hasta cierto punto autónomas- conforman una serie de registros visuales fundamentados en la pluralidad que simultáneamente los hace particulares como unidad simbólica. Una publicación no realizada para ser leída, en su concepción habitual, que se aleja de los caminos asignados como estandartes de la adquisición de conocimiento para alertar acerca de otro tipo de necesidades interdisciplinarias, aquellas que armónicamente fusionan la imaginación, la emoción, la sensación, sus representaciones y sus interpretaciones. Una integración -excéntrica en ocasiones- de palabra, imagen y objeto, que asume la asimilación de procesos generativos de nuevas relaciones creativas, de otras formas de entender la democratización del arte, de posiciones alternativas respecto a las leyes mercantiles, y al fin y al cabo, la evolución de los lenguajes y códigos verbales o gráficos. Es así como, con tirajes y difusión reducidos, apuntaba que "las revistas dejan de ser un medio de divulgación de ideas y se convierten en un espacio de creación" (Sarmiento en Bonet, Tro, y otros, 2010, p.57), un espacio repleto de vínculos provenientes de la indagación referencial que cada lector "proponga". Mientras la revista normalizada, estructurada y lineal, se rectifica de acuerdo a las temáticas generales de la misma o del número en particular, la ensamblada genera un conocimiento emotivo, a través del cual el lector debe interpretar cada "página" (pieza), en un escenario abierto a múltiples posibilidades narrativas y representacionales, que definen la subjetividad y la experiencia como principal estructura operacional.

Podríamos en este sentido importar la idea de la emancipación de la lectura de Millán y García (1975), en ellos referida a la autonomía de la escritura en la conciencia moderna a partir del análisis de la poesía experimental, eminentemente visual, en la que acontecen fenómenos espaciales que acompañan la significación ordinaria. Al transformarse en "espacios de creación", estas revistas suponen la exposición alternativa de contenidos y su separación de lo preexistente -aquello que anteriormente ya es considerado-, pues en estos términos "lo que no está formulado o fijado no existe" (Millán y García, 1975, p.18). Estas nuevas codificaciones diluyen anteriores "formatos" lingüísticos para asentarse como lenguajes de irrupción que el lector se ve imposibilitado a objetivar, ante los que ha de surgir como sujeto, espectador que demuestra y desvela su existencia, que rememora sus experiencias para comprenderlos y otorgarles sentido (Sarmiento, 1990). Se generan lapsos de narrativa propia del receptor respecto de lo que ve, lapsos de un tiempo no lineal, alejado de la textolatría expuesta por Barthes (1986), de la escritura como estructura básica de la información, que se convierten en fuente de cultivo visual no redactado, lleno de incertidumbre, sin una guía de sentido y con una desafiante postura hacia la polisemia del conocimiento y de las formas. Lógica que Lotman (2003), respecto del texto artístico, valoraría a partir de una doble dinámica vacilante que "por una parte, está orientada (...) a subrayar la 
importancia de las fronteras del texto, $\mathrm{y}$, por otra, a incrementar la heterogeneidad, la contradictoriedad semiótica interna de la obra, el desarrollo dentro de ésta de subtextos estructuralmente contrastantes que tienden a una autonomía cada vez mayor" (p.3). Es por lo que esta carencia de restricciones y tensión de integración interpretativa profesadas por las revistas ensambladas se escudan y protegen en un lector "sensible" y reflexivo, pues "no bastan ojos y manos para "leer" sus contenidos; sus propuestas perceptivas solicitan una implicación mucho más sensitiva y emocional." (Rodríguez, Gracia y Murciego, 2008, p. 241)

Anteriormente anotaba cómo habitualmente el contenido normalizado tiende a centrarse en el uso del lenguaje por medio de la relación texto-imagen, cuestión que la revista ensamblada puede o no utilizar, según sus intenciones. Y aunque "no hay pautas ni criterios definitivos, la fórmula ideal para conseguir un resultado de calidad se reduce a imaginación y colaboración" (Gómez, 2010, p.13), si en estas revistas reside texto o no, sin distinción, es porque su importancia no mora en la comunicación de información objetiva, de un mundo concreto, sino en una comunicación que no se centra en la lengua sino en los lenguajes, aquellos que no necesitan traducción por sus múltiples capacidades. Entenderemos por tanto que, su atención polisémica y multilingüíistica, complejice su elaboración. Es natural que el proceso creativo en las publicaciones convencionales se establezca -generalmente- en la normatividad editorial y los estudios de márquetin, mayormente enfajados y estipulados a priori, pues si bien puede indicar cierta coerción, resulta de gran comodidad a su divulgación por medio de los canales ya edificados. Un proceso que en la revista ensamblada, como vemos, debe componerse desde la autonomía sintáctica y la libertad práctica y estilística, en una ideación constante de alternativas. Retos que, si bien multiplican los riesgos, suponen dosis estimulantes de creación y superación autosuficientes.

Y todos estos términos también influyen el exterior de las revistas, su soporte y formato, pues en las primeras quedarían inscritos dentro de lo estipulado, y en las segundas, pueden ser tan diversos -incluso dentro de la misma publicación- como necesidades lingüísticas y comunicativas se encuentren. Mientras unas, dispondrían exquisitas tipografías, estudiarían calidades de papel, ilustraciones llamativas y experimentarían con los usos del color; las otras, cubrirían estas inquietudes desde la experimentación sobre los planteamientos a expresar y las reflexiones a interpretar, en cualquier formato y en cualquier técnica. De este modo, las revistas ensambladas conformarían idiolectos transformadores y proyectivos, originadores de "una conciencia creadora de ficciones" (Barthes, 1986, p.40) que, con otras sustancias, intelectualizan el mensaje al sustituir la señalización por la insinuación. Como "un complejo dispositivo que guarda varios códigos, capaz de transformar los mensajes recibidos y de generar nuevos", que adultera la habitual "fórmula 'el consumidor descifra el texto" por la de "el consumidor trata con el texto" (Lotman, 2003, pp.5-6).

\section{Algunos ejemplos}

Ejemplos de estos planteamientos anteriormente esbozados han habido muchísimos a lo largo de estos años, y sus diversos formatos y conceptualizaciones han dado muestra de ello. Lo que sigue, responde a un inventario panorámico acerca de este vasto 
campo, que pretende anotar algunas revistas que personalmente me han sorprendido por sus heterogéneos modos de actuación y estrategias de producción.

Enumerando grosso modo estas actuaciones, nos daremos cuenta de su versatilidad con revistas como: $B A O B A B$ (1978-1997, Italia), una de las primeras audiorevistas en casete con grabaciones de poesía sonora; Entretelas (desde 2005, España), la primera publicación periódica lavable y planchable, realizada con telas, fieltro y loneta de algodón serigrafiadas, en formato de periódico. En Pips (1986-2003, Alemania) y Container (1995-1998, España) encontramos revistas en caja, donde se incorporan objetos manipulados, postales, dibujos, diseños, etc. O Brain Cell (desde 1987, Japón), que incorpora estampaciones y sellos realizados por diferentes creadores. Pero cuanto más nos adentramos, mayor es nuestra admiración al ver la disparidad de propuestas que pueden recorrer desde el formato cartel $(100 \times 70 \mathrm{~cm}) \mathrm{de}$ Lo Straniero (1986-1993?, Italia) o un cubo como la revista de poemas La Pirámide (1990, España), a una bandeja desechable de poliestireno como Laurel (desde 2006, España).

Para comprender su multiplicidad podemos acudir a publicaciones como: La Bolsa (desde 2005, España), una revista en formato DVD que contiene vídeos experimentales de un máximo de 4 minutos, con una distribución bajo pedido. También podemos subrayar la revista enlatada Lalata (desde 2001, España), en la que según la temática de cada número se utiliza un recipiente diferente -aunque siempre bote-, que contenga los poemas visuales de todo tipo, bi o tridimensionales. Su tiraje ha fluctuado de 150 a 1200 ejemplares según el número, y puede contener de 1 a 98 obras originales, por lo que su costo también es variable. Otro curioso caso es el de La Wevera (desde 2008, España), con una temática por número profundizada en obras sobre huevos de porcelana y distribuida, evidentemente, dentro de hueveras que incluyen un folleto de la explicación del número y sus participantes. De las revistas ensambladas más polifacéticas, encontramos Pa'comer'Aparte (desde 2003, España), que cambia su formato y temática a cada número, que puede desplazarse desde una bolsa resellable, una botella de medicamento, maletines, bolsa de tela, a embalajes desechables de hamburguesa, estuches o cajas.

Algunas revistas ensambladas han optimizado su mercado, ampliando su tiraje y diversificándose en mayor alcance. Sería el caso de T-post Magazine (desde 2004, Suecia), una revista en formato de camiseta convencional, en la que cada cinco semanas viene estampado en su interior el post más votado en su página web durante este período. El exterior, la "portada" de la prenda, es estampado con una imagen realizada por diseñadores y artistas. Su distribución es bajo subscripción, en la que imprimen tantas camisetas como personas están adscritas a su revista. Otro caso similar, podríamos encontrarlo en Free Style Magazine (desde 2009, Alemania), una publicación periódica en formato de disco playero que funciona también bajo pedido.

Pero sin duda, un caso extraordinario sería el de la revista estadounidense Visionaire (desde 1991). Una publicación ecléctica considerada de las más caras de la historia, que altera su formato a cada número, según su temática. Para su realización se invita a personalidades del diseño, fotografía, música, arte, etc., a que conformen sus piezas para la edición de la misma. Sus contenedores han variado de juguetes, a cajas, porta cds, marcos digitales, camisetas de diseño, carpetas pop-up o maletines. 
Aunque algunos números no pasan de 170 dólares, la inclusión de originales ha elevado su precio a 3000 dólares ("Travel", número 2, 1991), o incluso a 5000 dólares en el número 18 ("Fashion special", 1996), que incluía fotografías y diseños exclusivos de moda ensamblados dentro de un bolso de Louis Voiton.

Para abandonar los excesivos precios de Visionaire, que sirvió como ejemplo fuera del margen, concluiré con otra revista ensamblada que alterna sus formatos en cada número, y que además, creo que conforma una muy válida estrategia híbrida entre la promoción divulgativa y la calidad conceptual ofertada: La Más Bella (desde 2003, España). Iniciando como una especie de fanzine de 100 ejemplares aproximadamente en su primer número, ha evolucionado, como vamos a ver, a una multiplicidad de géneros, estilos, formatos y adecuaciones que abarca ya los 1000 ejemplares. Partiendo entonces de su segundo número (1995), con una edición en formato de caja de pizza, sus contenedores han variado desde el estuche a un visor unipersonal de diapositivas o en $\mathrm{CD}$, lo que hace patente por un lado, las infinitas posibilidades teóricas y epistémicas que ofrece la libertad interpretativa del conocimiento abierto, y por otro, las confrontaciones que esto puede significar para la tradición de la lectura lineal -conclusa y disciplinar- y sus lectores.

Ejemplo muy claro de lo anterior, podemos observarlo en el número 9 de La Más Bella, cuya base temática era "Tú" (2003), no sólo como base de individualidad y otredad a la vez, sino como símbolo de identidad, aquella que se forma a través de la diferenciación y similitud con el resto. Contenidas en una cartera de mano, aquella en la que guardamos nuestra vida cotidiana, se ensamblan las interpretaciones de buena cantidad de objetos que cualquiera puede retener: tarjetas bancarias, de presentación, fotografías, etc. Este proceso simbólico surge primeramente del autor y su relectura transferida a la expresión en una pequeña pieza reconocible temáticamente, sin embargo, al formar parte de un conjunto resignificante mostrado como unidad ante el espectador, responde a un momento de reconocimiento y diferenciación. Lapso en el que este último se verá reflejado o extraño a lo allí mostrado y en el que se disparan las múltiples lecturas e interpretaciones acerca del individuo, de su personalización -individual y colectiva-, las heterogéneas visiones de lo que cada quien entiende y comprende de ese reconocible contenedor.

Y esta forma de trabajar, de profundizar en argumentos que posibiliten la apertura cognoscitiva y la diversidad perspectiva, es una tarea que La Más Bella se ha propuesto. Como en "Juegos Reunidos" (2005), y sus recreaciones lingüísticas a partir de la reinterpretación del bingo, la alteración de naipes, de juegos caseros, la modificación de tableros, etc., añadiendo nuevas significaciones a lo que de forma cotidiana reconocemos unilateralmente. O las conceptualizaciones de "Manual de instrucciones" (2007), número en el que se incluyen las más disímiles situaciones de lo que puede comprender una instrucción o incluso las herramientas que utilizamos para completarlas. Cada número es un singular espacio de compensación a la linealidad y forma de proceder habitual con una publicación periódica, que además, dada esta singularidad, también es distribuida peculiarmente a través de la máquina expendedora automática Bellamátic (2001) que la promociona sin horario restringido. 


\section{A modo de cierre}

Para concluir con este breve acercamiento sobre estas ediciones artísticas, anotaré que la existencia de este texto se debe principalmente a un interés que me estimuló tiempo atrás y que observó en estas publicaciones una riqueza representacional que nutre sobremanera las relaciones que se establecen entre lo interpretado, la multiplicación y reproducción artística, y una metamorfosis epistemológica sobre el mundo sensible. Todo ello contenido en un lugar común -de comunión-, en el que la tradición de conocimiento lineal se desvirtúa para dar paso a un despertar integrador. Formatos sin moda identificable que establecen nódulos para "construir una red relacional de sentido" (Vidal y Martín, 2010, p.6), y que necesitan reescribir y tergiversar las estructuras de la experiencia y de los límites del lenguaje para insistir en sus inmensas capacidades y sus bondades como lugar de encuentro.

Como hemos venido observando, abordar problemáticas de forma crítica desde la "interferencia entre la imagen y la literatura" (Bonet, Tro y otros, 2010, p.55) produce fracturas discursivas que abandonan los caminos hegemónicos del mundo editorial. Los mismos contenedores, los formatos y hasta sus conceptos, pertenecen a lo experimental, a singularidades y disidencias que alteran las dimensiones ya conocidas, para pasar a un estado de continuo tránsito en el que se "apuesta por la subversión de los códigos y tópicos sintácticos establecidos, abriendo las posibilidades de una nueva escritura completamente autónoma" (Huici citado en Bonet, Tro y otros, 2010, p.55). En ellas hemos visto cómo se posibilita la lectura expandida, su circulación entre disciplinas sumergiéndose en líneas fronterizas para disolverlas. Teniendo como base fundamental la colectividad y el networking, -entendidos como la conectividad social alejada de intereses económicos (Perneczky, 1993) -, los creadores de estas revistas, apoyados además por los nuevos soportes digitales, intercambian conocimientos y obras a distancia teniendo como eje la ilimitada comunicación sin centro y sin fronteras, urdiendo la trama o red en la que el producto artístico es el fruto del acto comunicativo y la interconexión de sus participantes.

Puede que los escritos acerca de las revistas ensambladas no hayan sido muy numerosos. Quizás la principal razón sea que como género o vertiente artística, como medio de comprensión comunicativa reproducible, sea tan heterogéneo y cambiante -en constante evolución- que desconcierte, que realmente resulte complejo reducirlo a tendencias, a modas, a estilos o categorías, aquellas que tanto nos agradan para estructurar nuestro mundo "ordenadamente". Pero pensemos que es posible que sea precisamente esta adaptabilidad a los tiempos, sus intervenciones, aplicaciones y posibilidades, las que primen como vía discursiva de estas publicaciones. Que sea esta perenne contaminación disciplinaria y lingüística a la que debamos recurrir para poder hablar de ellas, aunque resulte en ocasiones ininteligible o difícil de nominar. Es conocido que cuando carecemos de sustantivos para designar algo, ese algo se convierte en meta fuera de alcance, de arduo acotamiento de sus condiciones o de comprometido estudio - al menos tal y como lo conocemos-, pero posiblemente sea consecuencia de nuestras limitaciones al momento de ver, de entender, de leer, de escapar a lo lineal. 
Observamos ya que el concepto de Assembling se convierte genéricamente en el asignado a publicaciones, periódicas o no, fundamentadas en la "eliminación de las objeciones 'editoriales' y las interferencias" (Kostelanetz, 2001, p.37), objeciones que he intentado exponer brevemente en este escrito anotando aquello que de ellas he aprendido. Así, aunque muchos "ensamblajes" -y otros que vendrán- se han quedado en el camino, espero que estos ejemplos ofrezcan un somero panorama de estas actividades "aún" alternativas a lo hegemónico, por simbolizar el conocimiento en peregrinación, por presentarse como "un bricolaje entre el dictado del verbo y el imperio del ojo" (Bonet, Tro y otros, 2010, p.54).

\section{Referencias bibliográficas}

Barthes, R. (1986). Lo obvio y lo obtuso. Imágenes, gestos, voces. Barcelona: Paidós. Bonet, P.; Tro, G.; y otros. (2010). CAPS.A., la literatura i l art, Mataró 1982-1985. Barcelona: Institut Municipal d'Acció Cultural de Mataró.

Campal, J. L. (2001). Una ojeada a las revistas ensambladas. Edita 2001. VIII Encuentro Internacional de Editores Independientes y Ediciones Alternativas. 30 de abril, Punta Umbría (Huelva, España). Recuperado el 6 de septiembre de 2011, de la fuente http://www.merzmail.net/campalrevista.htm.

Gómez, A. (2007). Libros objeto y revistas ensambladas. El lenguaje y comunicación en los libros. Actas del Simposio de Archivos y Fondos Documentales para el Arte Contemporáneo. 30 de noviembre de 2007. Cáceres, España. Recuperado el 15 de julio de 2011, de la fuente http://boek861.com/proartista/pry/0\%20LA $\% 20$ AG.pdf.

Gómez, A. (2010). La revista ensamblada, una respuesta más. Artekiltro. Revista digital de letraskiltras. 3, 13-17. Recuperado el 23 de agosto de 2011, de la fuente http://issuu.com/letraskiltras/docs/ak3.

Kostelanetz, R. (2001). A dictionary of the avant-gardes. Nueva York: Routledge.

Latour, F. (2010). Books unbound. Wellesley Magazine, Otoño, 36-45.

Lipovetsky, G. (1996) El imperio de lo efimero: la moda y su destino en las sociedades modernas. Barcelona: Anagrama.

Lotman, I. M. (2003) La semiótica de la cultura y el concepto de texto. Entretextos. Revista electrónica semestral de Estudios Semióticos de la Cultura, 2, noviembre, pp.1-6. Recuperado el 11 de enero de 2012, de la fuente: http://www.ugr. es/ mcaceres/entretextos/pdf/entre2/escritos/escritos2.pdf

Martín-Jiménez, J. (2010). Reproducción repetición y reivindicación. Multiplicidad en el Arte Emergente Español. Madrid: Asociación Hablar en Arte

Millán, F. (2003). Apuntes sobre la década de los 70 en España. Poesía, transgresión, vanguardia y experimentalismo. Escáner cultural, año 5, 54, septiembre, s.p. Recuperado el 17 de julio de 2011, de la fuente http://www.escaner.cl/escaner54/ millan.html.

Millán, F.; García, J. (1975). La escritura en libertad. Antología de poesía experimental. Madrid: Alianza Editorial. 
Pastor, J.J. (coord.) (2008). Discursos sin norma. Ciudad Real: ACUA y Universidad de Castilla-La Mancha.

Perneczky, G. (1993). The Magazine Network: The trends of alternative art in the light of their periodicals, 1968 - 1988. Colonia: Soft Geometry Publications.

Rodríguez, A.; Clark, B. (2010). Revistas ensambladas. Entrevista a Antonio Gómez. Mombaça, 8, Invierno 2008, s.p. Recuperado el 21 de marzo de 2011, de la fuente http://laiguanaebria.blogspot.com/2010/02/antonio-gomez.html.

Rodríguez, J.A.; Gracia, R.; Murciego, J.; y otros. (2008). Hojeando... Cuatro décadas de libros y revistas de artista en España / Leafing... Four decades of artist's books and magazines in Spain. Barcelona: SEACEX.

Sarmiento, J. A. (1990). La otra escritura: La poesía experimental española. Cuenca: Universidad de Castilla-La Mancha.

Schraenen, G.; y otros (2010). Un coup de livres (Una tirada de libros) Libros de artista y otras publicaciones del Archive for Small Press \& Communication. Catálogo de la exposición homónima en el Museo de Arte Abstracto Español de Cuenca del 18 Junio - 31 Octubre de 2010. Madrid: Fundación Juan March.

Vidal, R.; Martín, O. (2010). De Zines. Madrid: Caja Madrid

\section{Referencias electrónicas}

Boletín Electrónico BOEK861 Mail Art y Poesía Visual: http://boek861.com/ Free Style Magazine: http://www.freestylemagazine.co.uk

La Bolsa: http://www.revistalabolsa.com

La Más Bella: http:// www.lamasbella.org

Lalata: http://www.lalata.es

Libro Objeto ST: http://libroobjetost.blogspot.com

Merz Mail: http://www.merzmail.net/mapa.htm

Pa'comer Aparte: http://www.pacomerapartearchivo.blogspot.com/

Pips: http://www.daton.de/pips/index.html

Red Libro de Artista: http://librodeartista.ning.com

Revista Objeto "Laurel": http://revistalaurel.blogspot.com

Richard Kostelanetz: http://www.richardkostelanetz.com

T-post Magazine: http://www.tpostmag.com

The book of Zines: http://www.zinebook.com/index.html

Visionaire: http://www.visionaireworld.com 